\title{
Event review: Seminário Nacional de Tecnologia Lítica, Goiânia, Brazil
}

\author{
Marcos Paulo de M. Ramos \\ Pontifícia Universidade Católica de Goiás. Rua 3, 350 - St. Central, Goiânia - GO, Brazil. \\ Email: argonauta128@gmail.com
}

Between 5 and 9 October of 2016 the Seminário Nacional de Tecnologia Lítica (National Seminar of Lithic Technology) took place on the campus of the Pontifical Catholic University of Goiás, Brazil. The seminar aimed to create a space of exchange and learning among students, researchers and professors which currently work with prehistoric lithic technology, developing studies in different regions of Brazil, in addition to the special participation of a researcher from Peru. The event was conceived and developed through the efforts of three Brazilian institutions: the Pontifical Catholic University of Goiás (Dr. Sibeli A. Viana and Marcos Paulo Ramos), the University of Pelotas, Rio Grande do Sul (Dr. Maria Gluchy), and the Federal University of Minas Gerais (Dr. Jacqueline Rodet), in addition to a partnership with Paris West University Nanterre La Défense (Dr. Eric Boeda). Activities of practical analysis on lithic material and knapping were developed with the aim of better understanding the methods and techniques involved in the production of archaeological tools. As the event sought to develop practical activities, with dynamic ones, it was accompanied by monitored knapping sessions. It was necessary to restrict the participation to a small number of people (20). Still, there was participation by students from undergraduate, master's, and doctoral programs. As well, places were reserved for archaeologists working with rescue projects involving lithic period sites.

All around, participants were all able to present issues related with currently developing research. A panel discussion of theoretical approaches applied in each research was held which provided an opportunity for a rich contact with the specifics of each lithic set as contextualized from regional paradigms throughout Brazil. Professors and organizers presented and explored the considerations of current theoretical and methodological approaches through the use of various analyses applied to the lithic collections with which they are currently involved.

The knapping exercises occurred primarily over three days. Professor Eric Boëda, from Paris West University Nanterre La Défense, collaborated intensely in this, sharing his experience of over forty years of knapping. It was clear to all participants that there is a heuristic importance in understanding the gestures and the forces applied in the knapping process on different raw materials. This national seminar is the first edition of a planned series. The next is expected to occur in the middle of the second half of 2017 in Pelotas (Rio

Published by the School of History, Classics and Archaeology, University of Edinburgh ISSN: 2055-0472. URL: http://journals.ed.ac.uk/lithicstudies/

This work is licensed under a Creative Commons Attribution 2.5 UK: Scotland License. 
Grande do Sul). For information about the next event, please contact the organisers via email (seminarionacionaldetecnologialitica@hotmail.com).

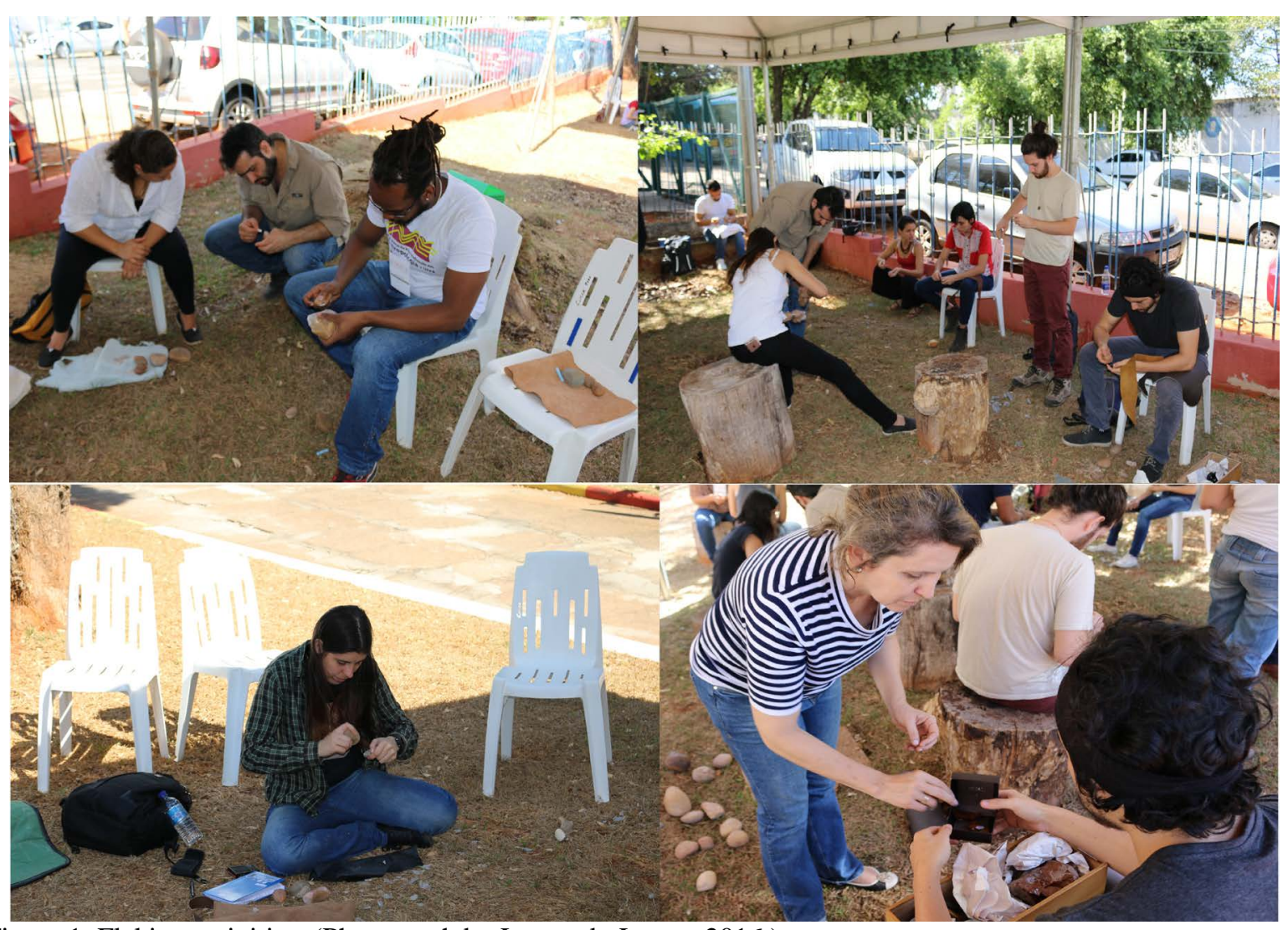

Figure 1. Flaking activities. (Photograph by Leonardo Lopes, 2016.)

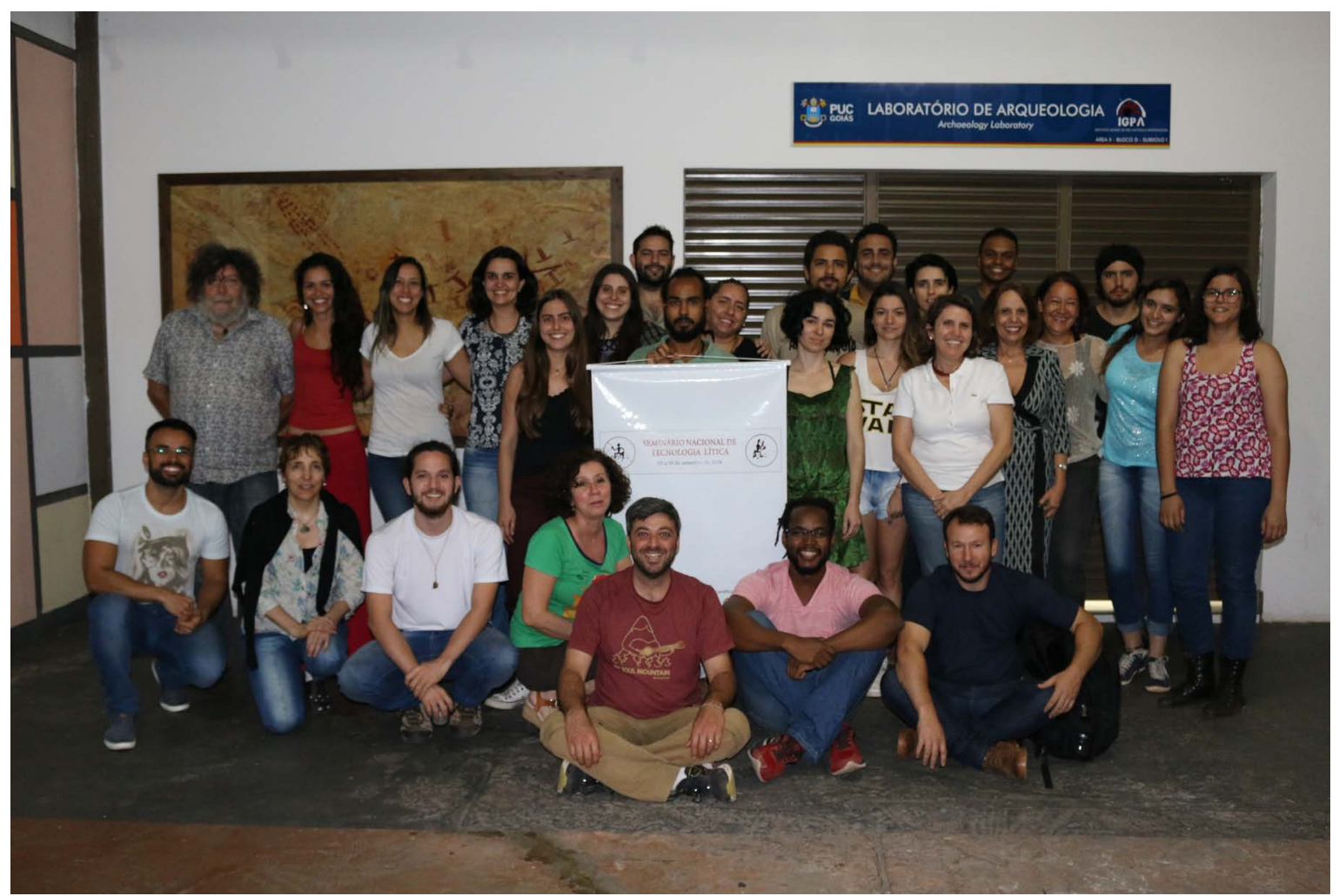

Figure 2. Participants and organizing team of Seminário Nacional de Tecnologia Lítica. (Photograph by Lorena Borges, 2016.) 